\title{
Lo líquido del espacio: una mirada hacia habitar contextos educativos.
}

\section{Space's liquidity: A look towards inhabiting educative contexts.}

\section{Miriam Peña Zabala}

Universidad del País Vasco

miriam.pena@ehu.eus

Regina Guerra Guezuraga

Universidad del País Vasco regina.guerra@ehu.eus

\section{Ana Urrutia Rasines}

Universidad del País Vasco

ana.urrutia@ehu.eus

Miren Josu Arriolabengoa

Universidad del País Vasco

Miren.arriolabengoa@ehu.eus
Recibido 15/09/2020 Revisado 09/10/2020

Aceptado 09/10/2020 Publicado 30/04/2021

\section{Resumen:}

Este artículo es parte de la reflexión de una investigación más amplia de un grupo de docentes universitarios, alumnado y personal administrativo de la Facultad de Educación de Bilbao, que reflexiona cómo resignificar el espacio social de la propia facultad.

Situamos nuestra investigación en los relatos extraídos de los miembros del grupo en una primera fase del proyecto, donde nos preguntamos cómo nos afecta el espacio y cómo lo concebimos, qué posicionamiento pedagógico adoptamos y qué tipo de relaciones creamos si hacemos nuestra la noción de lo líquido que recoge Bauman (2006).

El objetivo principal ha consistido en trazar unas líneas que propicien nuevas estrategias pedagógicas y relacionales en nuestro centro. Para ello tomamos el Fotoensayo como una herramienta que propicia dialogar desde lo visual, generar nuevas sinergias y profundizar en la conceptualización de lo que significa reflexionar sobre el espacio social de la Facultad de Educación de Bilbao y su proyección pedagógica.

\section{Sugerencias para citar este artículo,}

Peña Zabala, Miriam; Guerra, Regina; Urruutia, Ana; Arriolabengoa, Miren (2021). Lo líquido del espacio: una mirada hacia habitar contextos educativos. Tercio Creciente (Monográfico extraordinario V), (pp. 29-47), https://dx.doi.org/10.17561/rtc.extra5.5758

PEÑA ZABALA, MIRIAM; GUERRA, REGINA; URRUTIA, ANA; ARRIOLABENGOA, MIREN Lo líquido del espacio: una mirada hacia habitar contextos educativos. Tercio Creciente (Monográfico extraordinario V) abril 2021, pp. 29-47, https://dx.doi.org/10.17561/rtc.extra5.5758 
Abstract:

This article is part of the reflection of a broader investigation of a group of university teachers, students and administrative staff of the Faculty of País Vasco, which ruminates on the redefinition of the social space of the faculty itself.

In the first phase of the investigation we place our research on the stories extracted from the members of the group, where we ask ourselves how space affects us and how we conceive it, what pedagogical position we adopt and what type of relationships we create if we make the notion of liquid, as Bauman gleans (2006), our own.

The main objective has been to draw lines that contribute to new pedagogical and relational strategies in our center. For that purpose we take the photo-essay as a tool that encourages dialogue from the visual, generates new synergies and deepens the conceptualization of what reflecting on the social space of the Faculty and its pedagogical projection means.

\section{Palabras Clave:}

Espacio social; lo líquido; práctica docente; fotoensayo; relaciones

Key words:

Social space; liquid, teacher practice; photo-essay; relationships

Sugerencias para citar este artículo,

Peña Zabala, Miriam; Guerra, Regina; Urruutia, Ana; Arriolabengoa, Miren (2021). Lo líquido del espacio: una mirada hacia habitar contextos educativos. Tercio Creciente (Monográfico extraordinario V), (pp. 29-47), https://dx.doi.org/10.17561/rtc.extra5.5758

PEÑA ZABALA, MIRIAM; GUERRA, REGINA; URRUTIA, ANA; ARRIOLABENGOA, MIREN Lo líquido del espacio: una mirada hacia habitar contextos educativos. Tercio Creciente (Monográfico extraordinario V) abril 2021, pp. 29-47, https://dx.doi.org/10.17561/rtc.extra5.5758 


\section{Introducción}

La necesidad de repensar los espacios que posibiliten la visibilización de los agentes que somos parte de toda relación pedagógica es esencial para el aprendizaje. Cuando las personas habitan un espacio de forma fluida, éste se vuelve más dinámico y participativo. Aparecen los matices, el reflejo de todas las realidades que conforman la sociedad. Es entonces cuando lo normativo se agrieta para dar lugar a otras voces.

Desde esta creencia, este trabajo es parte de una investigación más amplia que recoge las voces de un grupo de docentes universitarios, alumnado y personal administrativo de la Facultad de Educación, que reflexiona cómo resignificar el espacio social de la propia facultad que habita en su quehacer diario.

Concebimos el espacio como una herramienta susceptible de ser repensada desde lo performático, como un núcleo material donde los elementos visuales y sonoros (...) influyen en la vivencia y el vínculo hacia un lugar, despiertan emociones y favorecen las relaciones que, a su vez, son necesarias para que el espacio tenga vida y adquiera significado.

Entendemos el espacio como un lugar líquido en constante transformación y evolución, desde una concepción y visión poliédrica donde tienen cabida aspectos no sólo funcionales sino también emocionales. Desde este posicionamiento se defiende que el espacio no es únicamente un lugar de tránsito sino que debe ser un lugar habitado en el que emerge el ecosistema vinculado a las pedagogías del afecto. Nos encontramos ante un espacio que debe favorecer la colaboración y la comunicación entre las personas a través de ese todo que nos conforma, que ha de crear sentido de pertenencia y vínculo y debe convertirse en un lugar de encuentro que confluya repensandose de manera compartida. Se hace necesario un espacio inclusivo, donde quepa la diversidad y la aceptación del otro que soy yo y donde nos podamos construir como actores sociales en la relación con los demás. 
Sin embargo, la vinculación a la norma y al protocolo, la saturación del sistema, la búsqueda de la funcionalidad y el ritmo precipitado en las acciones diarias (...) contribuye a que a menudo no se produzcan las relaciones deseadas en el espacio compartido, o a que ocurran de un modo velado, restándole protagonismo y esfumándose a veces si no se le presta atención. Es entonces cuando el espacio social que habitamos se convierte en un lugar de paso carente de significado emocional donde predomina lo funcional. En esta tesitura se aprecia la necesidad de salir de una visión antropocéntrica del sujeto como único protagonista de aquello que ocupa, concebir diferentes maneras de vivir los espacios, dar cuenta de los ecosistemas de relación inherentes a ocuparlos, y dotarlos de significado donde todo es sensible de ser protagonista para la construcción de sentidos, de saberes, de afectos.

\section{La mirada a un espacio habitado}

La idea de espacio social como materia prima de lo que puede significar habitar en la Educación surge de la conveniencia de utilizar más espacios — de otro tipo- diferentes al aula convencional donde llevar a cabo tanto actividades que requieren metodologías activas como dinámicas de grupo diversas. Se busca mirar más allá del orden del aula, de la fracción, de lo previsible que en un lugar se puede dar, para activar otro tipo de sensibilidades vinculadas a una sensibilidad estética rica y plural, entender la noción de habitar como algo que acompaña en la construcción de lo que somos, siempre presente y siempre parte de lo cotidiano.

Estos últimos son factores que se consideran esenciales en la formación de un alumnado que se verá obligado a interactuar y a tener que gestionar el espacio donde tenga que trabajar como futuro docente. Por lo tanto, se desprende de estas ideas que despertar la conciencia hacia el espacio social como una herramienta educativa, puede derivar en una estrategia significativa que propicie recursos para una educación de calidad, en la que el sujeto es parte de su propio aprendizaje a partir de aquello que le rodea. De algún modo el sujeto deja de ser el centro, el núcleo sobre el que se gira, para pasar a ser uno más que se nutre de lo otro y viceversa. El contexto y todo lo que se haya o acontece en él es parte de los procesos de aprendizaje y para ello tomamos prestada la reformulación de la noción de contexto en términos de un despliegue de contexture (contextura) (Jornet y Roth, 2018 en Jornet y Erstad (2018)), el cual da lugar a que las personas y los materiales cambian dentro de una relación constitutiva mutua. Jornet y Erstad (Ibid.) hacen con este contexto una analogía con las cuerdas y los hilos que las componen, donde todo lo discernible dentro de un contexto se junta de tal modo que forma nuestras vidas particulares, identidades e historias. 
Por ello se quiere incidir en las posibilidades para construir aprendizaje que ofrecen diferentes espacios de la Facultad de Educación, y activarlos hacia la toma de conciencia de la variedad de factores relacionados con el espacio, que entran en juego en los procesos de aprendizaje, como también son, la ocupación, la resistencia y el empoderamiento hacía lo propio, para finalmente generar un contexto de pertenencia que te vincule a un lugar y lo hagas tuyo.

El vacío que se produce en algunos espacios por los que se circula en nuestra rutina universitaria fomenta la desconexión entre el alumnado y la institución encargada de su formación. Desde la creencia de que el espacio y su disposición tienen una gran influencia en el comportamiento individual y colectivo del personal que convive dentro de la universidad, si no se pone el acento en ello, puede dejar de ser un espacio cargado de potencialidades y convertirse en un no lugar (Careri, 2002) que cumple una función meramente estructural.

Los lugares donde generamos acciones educativas y los espacios que nos envuelven al compartir experiencias de aprendizaje pueden resultar atractivos y motivadores o, por el contrario, y como suele ser habitual, convertirse en sitios que llegan a entorpecer cualquier intento de innovar o avanzar (Huerta y Domínguez, 2015, p.11).

\section{Una mirada docente}

Todo aquel que habita un espacio se convierte en un engranaje que lo vehicula. Toda vivencia es sensible de ser repensada dependiendo de la experiencia vital desde la que se mire. En este caso abordamos este texto desde una parcialidad, desde un enfoque docente, desde la potencialidad que podemos intuir si abordamos la vivencia del espacio social como el modo desde donde afrontar nuestra práctica docente, y no tanto como una alternativa o un recurso al que recurrir parcialmente. Desde la perspectiva del PDI (Personal Docente Investigador), se cree que una reflexión sobre lo que significa habitar un lugar y su posterior acción en el contexto del espacio social visibiliza las oportunidades que ofrece la Facultad de Educación. En un paradigma educativo de futuro incierto se esboza una emergencia en la que otros modos de acercarnos al conocimiento se tornan posibles, donde se puede transformar el continente de la acción docente como una urgencia paradigmática, y perder el miedo de traspasar la línea virtual del aula cuando las circunstancias lo propicien. 
Bajo esta premisa en la Facultad de Educación concurre alumnado de tres Grados, numeroso PDI y PAS (Personal de Administración y Servicios). Más allá de la mera ocupación de un espacio, esta propuesta nace desde el cuestionamiento de qué sucede en los flujos de los espacios, en unos espacios que nos afectan por el mero hecho de habitarlos. Desde esta afirmación se cree imprescindible tomarlo en cuenta como un eje de acción que puede llevar a la mejora de las relaciones, hacia la conexión significativa de todos aquellos que al fin y al cabo vivimos en la Facultad y ocupa una gran fracción de nuestra vida.

Desde la creencia de que el ser humano aprende descubriendo sus puntos fuertes y habilidades en un entorno adecuado para esa autodeterminación (Müller, 2010), el espacio social como materia prima se convierte en un agente no prescindible en la formación del profesorado, ya que desde la creencia de que "no existe pasividad ante el entorno" (Pérez Fernández, 2004, p. 162), este nos conforma y transforma. Loris Malaguzzi, impulsor de las teorías que articulan Reggio Emilia, defiende que el espacio social funciona como articulador de conocimiento e incluso ha llegado a definirlo como el tercer profesor, asignándole un estatus de gran relevancia en lo que significa un proceso educativo. Creemos que el aprendizaje se produce desde la relación con los demás y que el espacio es fundamental para fomentar las relaciones, para crear vínculos de pertenencia y generar recuerdos por lo que, a su vez, resulta necesario para mejorar la calidad de la educación.

Algo ocurre cuando algunos investigadores docentes reivindicamos el espacio social como algo que no puede ser obviado, y otros agentes educativos ni tan siquiera lo consideran como una variable a tomar en cuenta. Quizá es interesante abordar esta contradicción desde una visión más global y entender que este modo de visibilizar la estructura educativa no es más que un reflejo de cómo se articula y estructura la sociedad actual (Di Masso, Berroeta y Vidal, 2017).

Por lo tanto, si el colectivo docente puede reposicionarse y moverse, se permite un sentido compartido de liderazgo y la jerarquía profesorado-alumnado-institución es menos marcada. Pero, ¿estamos preparados los docentes para sucumbir a lo líquido que espera fuera del aula? No nos referimos a la ausencia de rigor, ni a unos objetivos pedagógicos ontológicamente vagamente definidos, sino de aceptar lo otro como una oportunidad en relación, acogerlo inmediatamente, como si no pudiese ser de otro modo, hacer de la oportunidad una protagonista de la ecuación pedagógica. Esto necesita de recolocación, de repensar lo que interfiere en la función docente, de las relaciones poder-conocer (Tardif, 2010) y como se coloca el docente frente a estas. 
Cuando esto ocurre, cuando el docente habita un lugar de modo reflexivo donde un modo de estar líquido se convierte en un modo de estar consciente y no en una parcialidad, es entonces cuando la matriz de aprendizaje cambia, y el discente actúa inevitablemente vinculado, y existe la posibilidad de que se empodere en relación a los procesos de aprendizaje. Unas ramificaciones invisibles se extienden al mismo tiempo en el que encontramos un lugar de esparcimiento para ser nosotros mismos. No hay que tener miedo a su expansión ya que este no es más que un tejido que nos sujeta.

\section{Metodología}

Pensamos que la Investigación Basada en Artes posibilita dar a conocer esas subjetividades en relación con el espacio que nos rodea y nos permite ser. Este método de investigación no pretende reemplazar las tradicionales maneras de hacer investigación, más bien es visto como una despensa de métodos, desde la cual el equipo investigador puede referirse al tema de interés (Barone \& Eisner, 2012, p.170).

Nos apoyamos en el foto-ensayo ya que nos facilita representar las reflexiones extraídas de las narraciones de una manera visual, en la que el conjunto de imágenes presentadas da cuenta de una visión subjetiva de cómo entendemos estos espacios, dejando abierta la interpretación de estas. Según Roldán y Marín (2012, p.78) "cada una de las fotografías que configuran un foto-ensayo y, sobre todo, las interrelaciones que establecen unas imágenes con otras, van centrando sucesivamente las posibles interpretaciones y significados hasta conformar con suficiente claridad una idea o razonamiento". En el caso de nuestra investigación, nos centramos en el carácter líquido del aprendizaje y su capacidad de llenar o de filtrarse por los resquicios de los objetos o espacios que lo contiene.

Barone y Eisner (2012, p.169) justifican que la calidad de una investigación basada en el arte depende de su capacidad para permitir que los perceptores de la obra vean aspectos del mundo social de nuevo, lo que los impulsa a reexaminar el valor y la utilidad de su propia perspectiva predominante con respecto a esas características. Nuestro objetivo es, por medio del conjunto de imágenes, permitir una nueva manera de acercarnos a la compresión de los espacios sociales, darle visibilidad a la manera en la que nos relacionamos con estos y mostrar diferentes modos de representar dichas relaciones, dejando a un lado lo fijo y estanco para centrarnos en el estado líquido de las cosas. 


\section{Fases de trabajo y propuesta}

En base a lo que el fotoensayo nos puede aportar como método visual de investigación, las autoras toman la noción de "lo líquido" como detonante reflexivo desde el que trabajar. En base a esta premisa se generan 3 fases de trabajo. Desde un punto de vista colectivo, la propuesta presentada posibilita activar detonantes hacia una facultad viva, de encuentros, donde las relaciones emergen por el mero hecho de habitar un espacio. Esta creencia permite pensar en un lugar en el que los diferentes colectivos se acercan, se mezclan, donde las diferencias se difuminan o se enriquecen para ser todos habitantes de un mismo lugar.

\section{Fase 1}

Cada autora se sumerge en un contexto de producción creativo autónomo. Se toma como punto de partida una metáfora trinomio que comprende el contenido (lo líquido), continente (objeto) y contexto (ambiente) como herramientas con las que trabajar. Hablamos de cualquier continente que permita jugar con la transparencia, con la noción de llenado, con lo traslúcido, y quizá lo más importante con ponerlo en relación con el otro. El modo de hacer es libre, sin una cantidad de fotografías estipulada. Toda creación que cumpla el mencionado trinomio contenido continente y contexto es bienvenido. Nos alejamos de la creación bella y aceptamos el boceto quizá como detonante de un discurso o como una imagen que pueda articularse con otra y subraye su significado.

\section{Fase 2}

Nos sumergimos en una puesta en común que articula derivas y discursos que generan detonantes con los que dialogar. Cada autora explica las fotos realizadas. Intenciones, estrategias utilizadas y exposición de variedad de contextos y continentes, que propician que se articulen las reflexiones en torno a lo significativo del espacio líquido.

\section{Fase 3}

Cada participante hace una selección de imágenes que ayuden a sintetizar las ideas principales de su discurso. Desde un posicionamiento en que todo convive en relación y se resignifica en relación al otro, abordamos una composición de imágenes que recoja tanto imágenes de creación propia como el uso libre de imágenes de las compañeras.

Para la creación de estas composiciones se adopta un modo de maquetación no lineal, con cierta secuenciación en algunos casos pero con variedad de espacios de vacío, de respiro y escalas aleatorias. Se intenta de este modo no buscar una direccionalidad de la lectura, sino que la mirada busque un foco en el que fijarse que permita generar analogías con el pequeño texto que se ha redactado paralelamente a la imagen. 
ISSN: 2340-9096

\section{Resultados}

Nuestra reflexión sobre cómo nos relacionamos con y en el espacio nos lleva a preguntarnos cómo nos afecta el espacio y cómo lo concebimos, qué posicionamiento pedagógico adoptamos y qué tipo de relaciones creamos. ¿Qué ocurre desde nuestra práctica docente cuando habitamos un espacio?
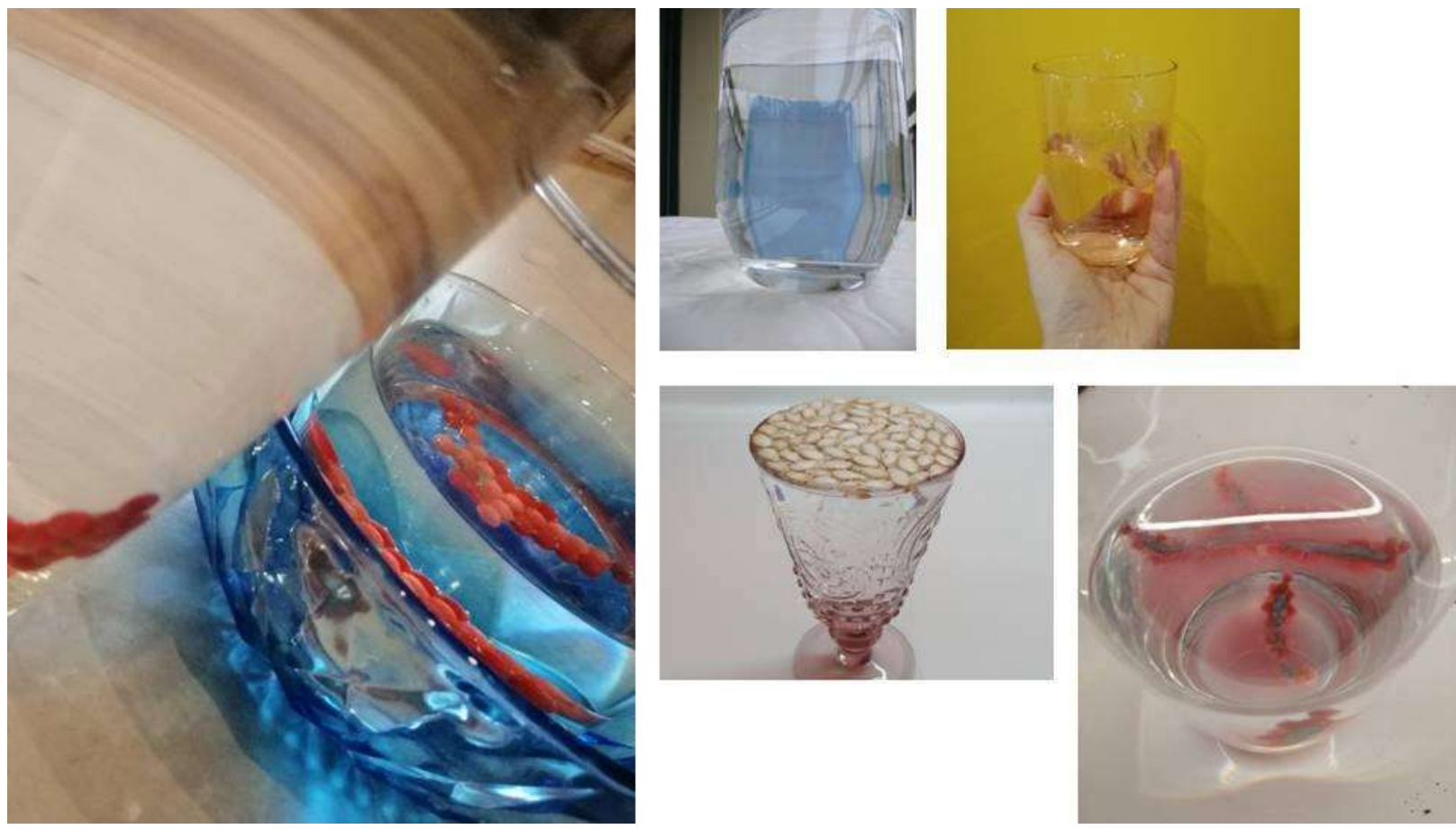

Figura 1. Fotograma 1. Autoría propia.

El agua como metáfora de un posicionamiento educativo. Un estado líquido que permite transformar y, en consecuencia, repensar el ecosistema en el que se encuentra por sus ricas posibilidades de, y por los nuevos encuentros que el devenir propicia, a través del agua un ecosistema, nunca resuelto, siempre expansivo, siempre en relación. 
ISSN: $2340-9096$

https://doi.org/10.17561/rtc.extra5.5758

\section{@}
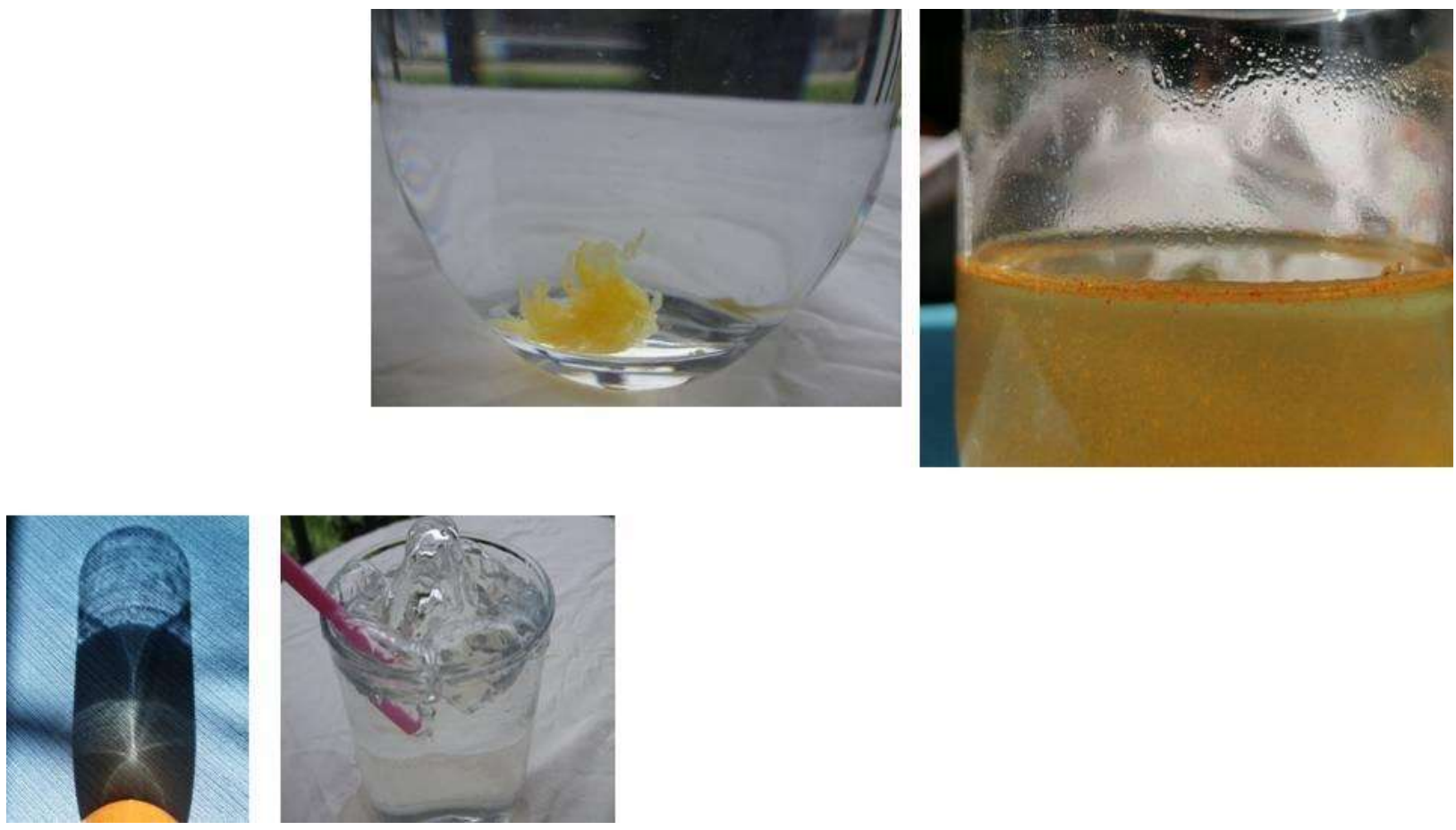

Figura 2. fotograma 2. Autoría propia.

El agua es la representación de un modo de estar expansivo, afectado por su estado líquido que no perdona y su afán de ocuparlo todo, su posibilidad de transformación y sus numerosas posibilidades de relación con y en el ecosistema en que se encuentra. 
ISSN: 2340-9096

Abril 2021

https://doi.org/10.17561/rtc.extra5.5758
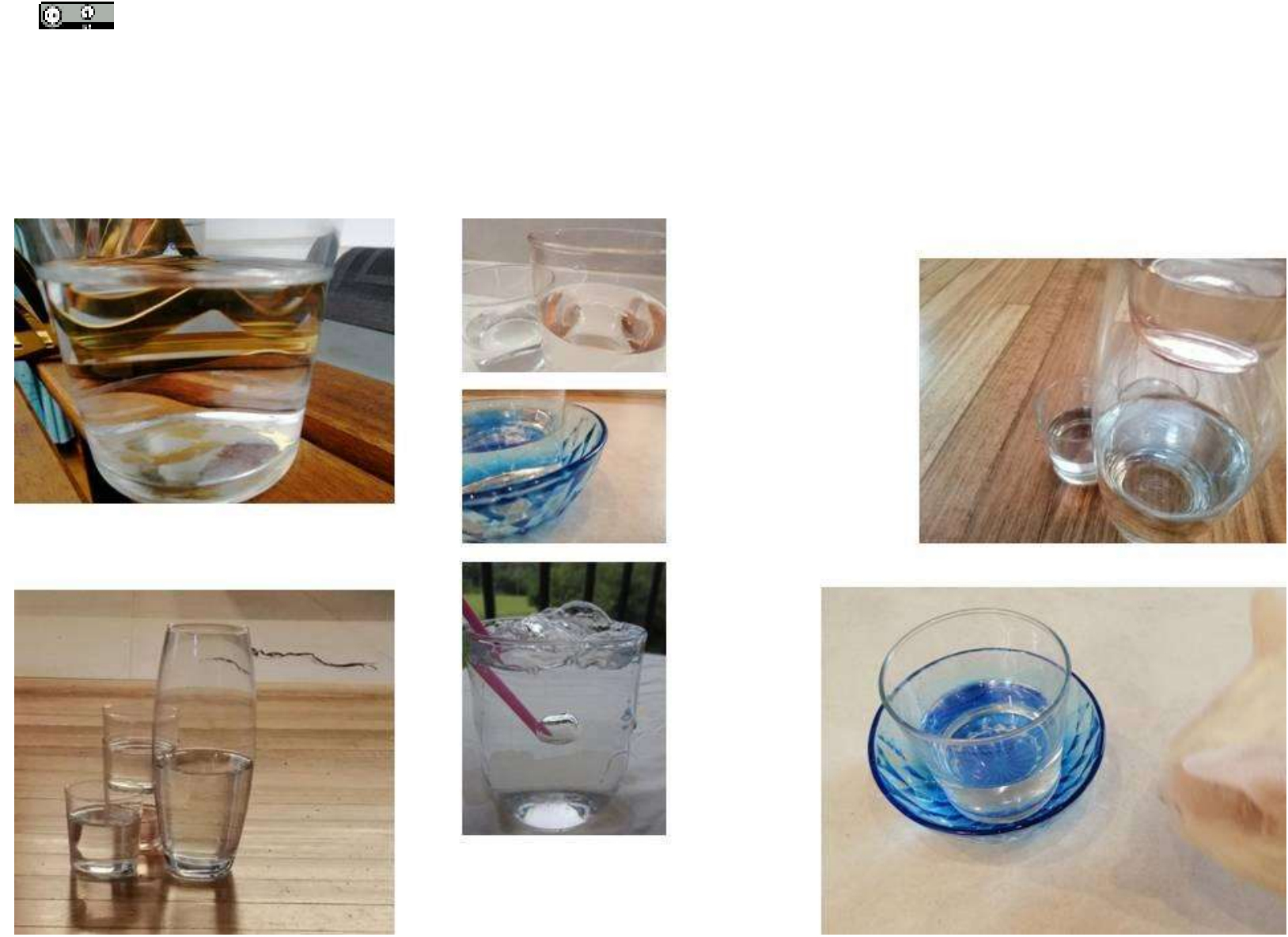

Figura 3. Fotograma 3. Autoría propia.

La relación entre diferentes genera extrañeza y lo inesperado. Deforma nuestra realidad, dándole una nueva manera de ser representada y repensada. Una más sugerente, más profunda, en la que lo que está atrás pasa quizá a un primer plano, pero hay que estar predispuestos a la deformación descontrolada que solo es posible si lo fluido interfiere. 
ISSN: $2340-9096$

https://doi.org/10.17561/rtc.extra5.5758

\section{@}
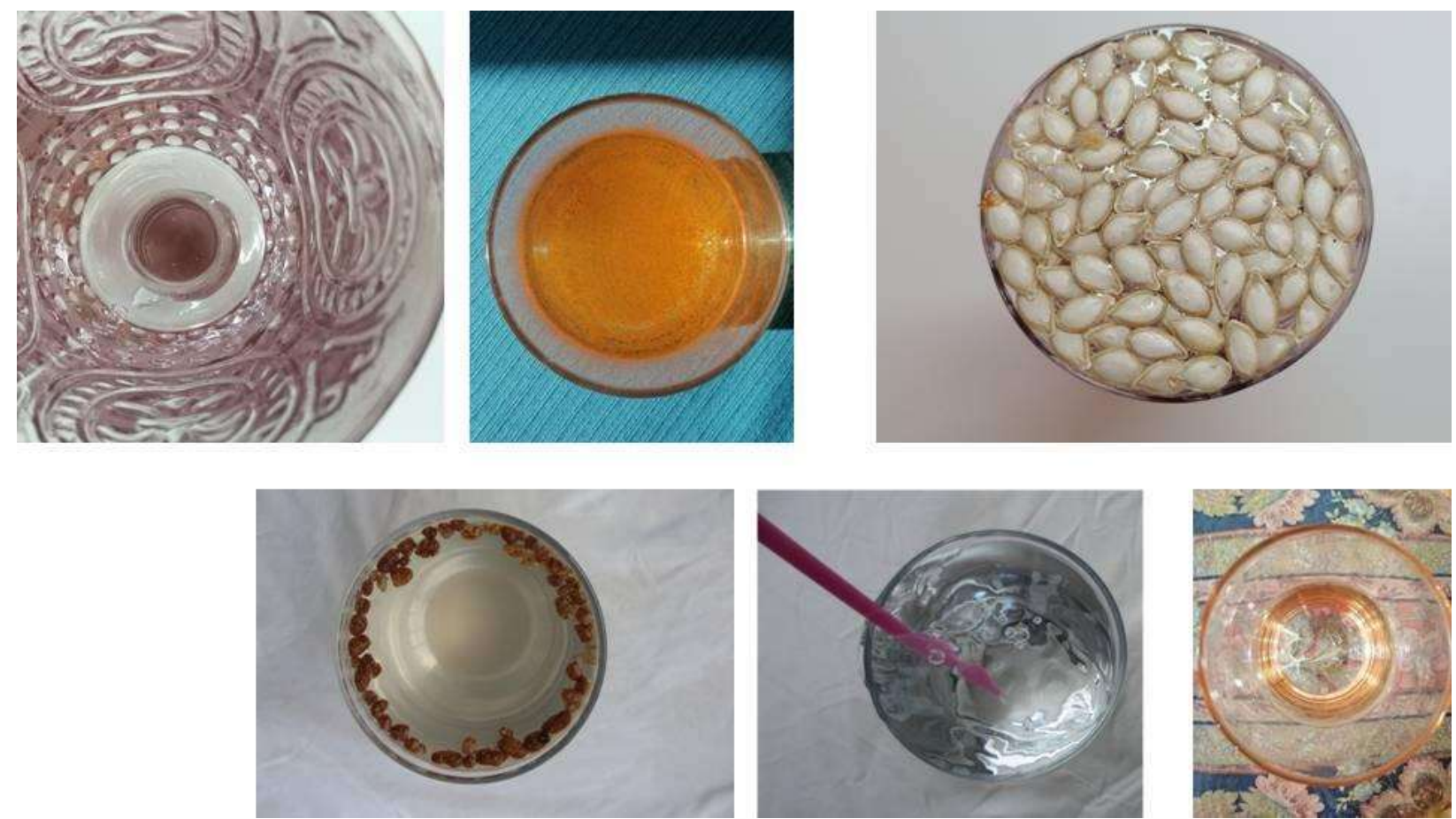

Figura 4. Fotograma 4. Autoría propia.

El fondo común cambia, según quién sea la persona que lo habite o según por quién o qué pase la luz. El cómo también influye. ¿Está el espacio ocupado? ¿Cómo hago para pasar desapercibido? y, ¿para llamar la atención? ¿Saben que estoy ahí? ¿Acaso mi transparencia me hace invisible? Si el agua invade todo, ¿somos capaces de ver si lo ocupa todo? La extrañeza necesita una estructura. 
ISSN: $2340-9096$

https://doi.org/10.17561/rtc.extra5.5758
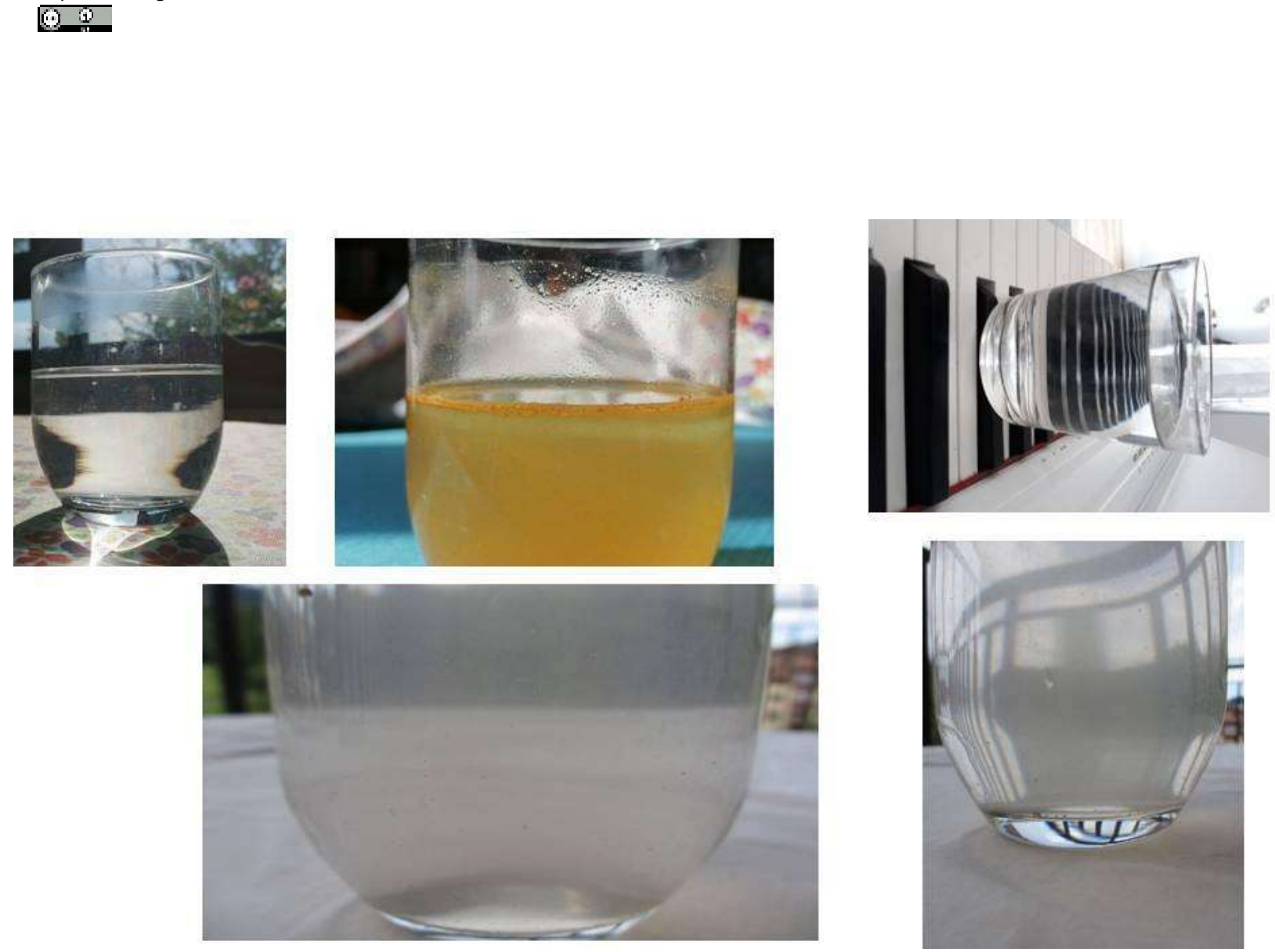

Figura 5. Fotograma 5. Autoría propia.

Lo líquido ocupa en su totalidad todo lo que habita, llegando incluso a convertirse en invisible, se trata de una estrategia de supervivencia incluso, camuflado con su entorno. Es una existencia que empapa todo a su alrededor, sin dejar huecos, entrando en cada resquicio del espacio. Afecta en lo personal, nos deja calados, fríos e incluso tiritando. Temblamos. Porque también ocurre que algo más grande que nosotros nos rodea, y cabe la posibilidad de que pertenezcamos a algo mayor que nos nubla. 
ISSN: $2340-9096$

https://doi.org/10.17561/rtc.extra5.5758

\section{(1)}
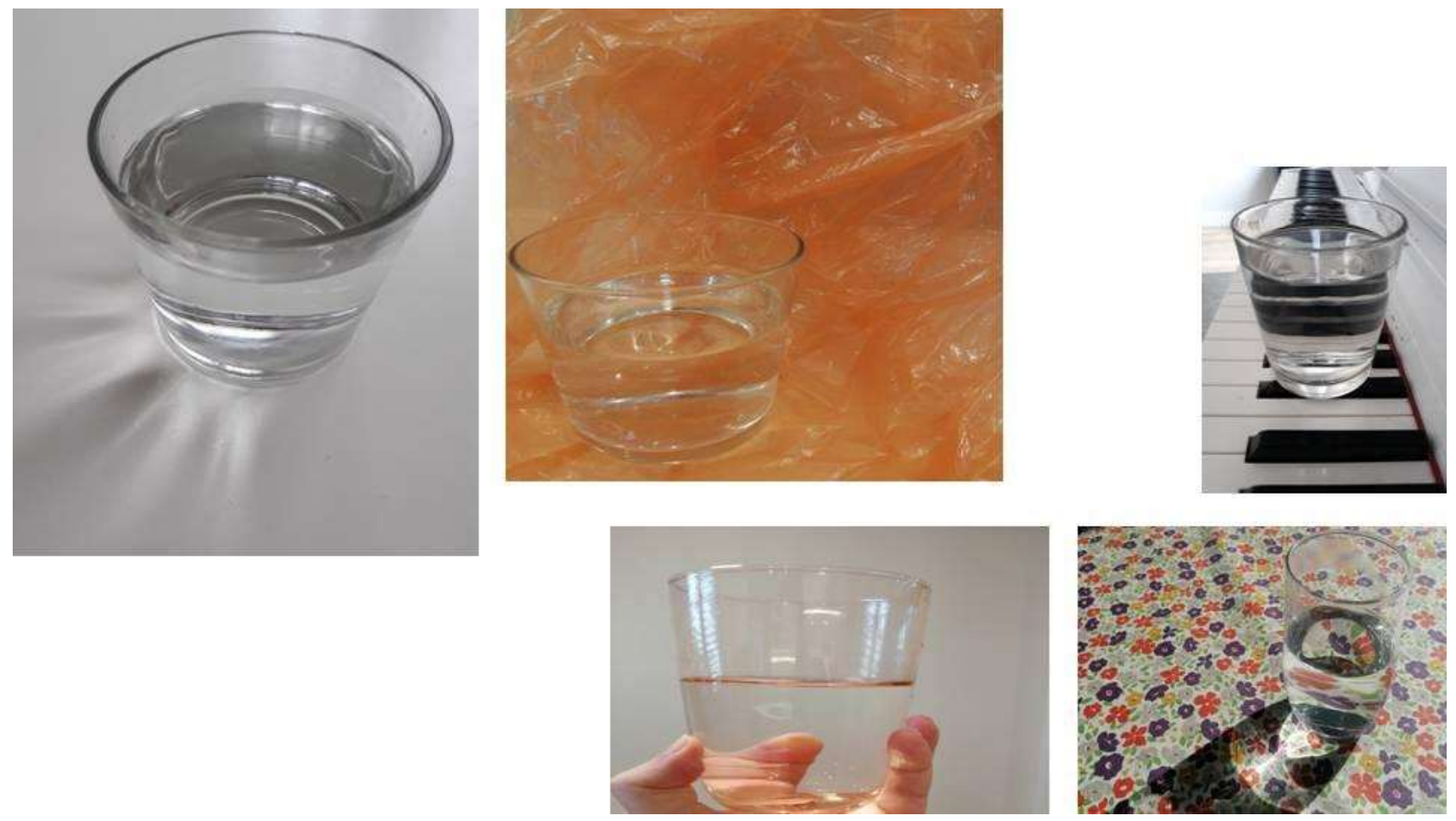

Figura 6. Fotograma 6. Autoría propia.

Los rastros de lo húmedo en las paredes del vaso, que no son posibles si el agua no ha pasado por ahí. A veces no sabemos si ese líquido está o no, y hasta puede que no se vea, pero resulta completamente esencial para que lo que vemos suceda. 
ISSN: $2340-9096$

https://doi.org/10.17561/rtc.extra5.5758

(i) (i)

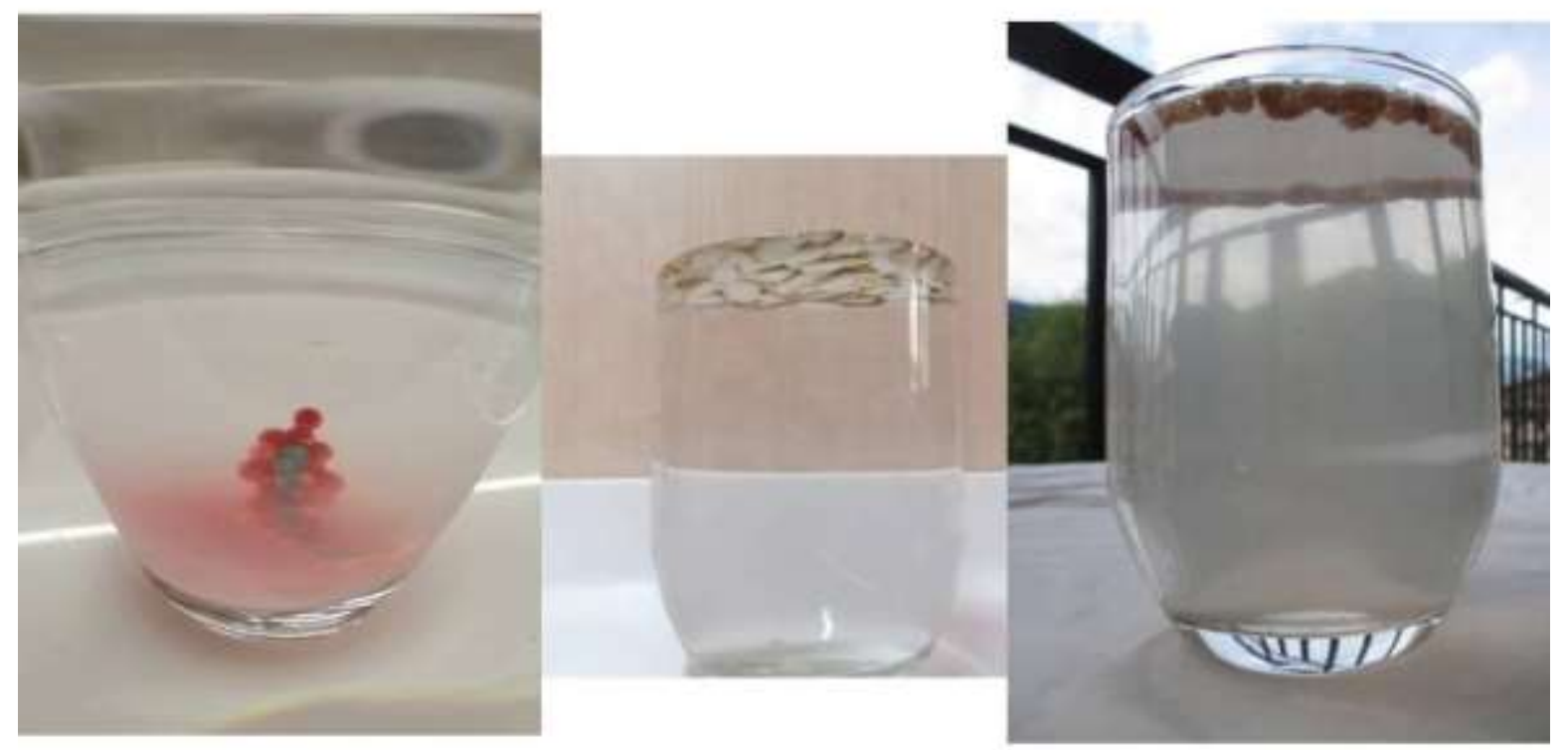

Podemos decir entonces que los entornos líquidos posibilitan habitar los espacios, cada cual desde su ser, expandiéndose, replegándose, interactuando, evolucionando.

Sumergirse es sinónimo de búsqueda, de explorar y experimentar.

Cabe surgir, diluirse, desaparecer. 


\section{Tercio Creciente}

ISSN: $2340-9096$

https://doi.org/10.17561/rtc.extra5.5758

\section{(1)}
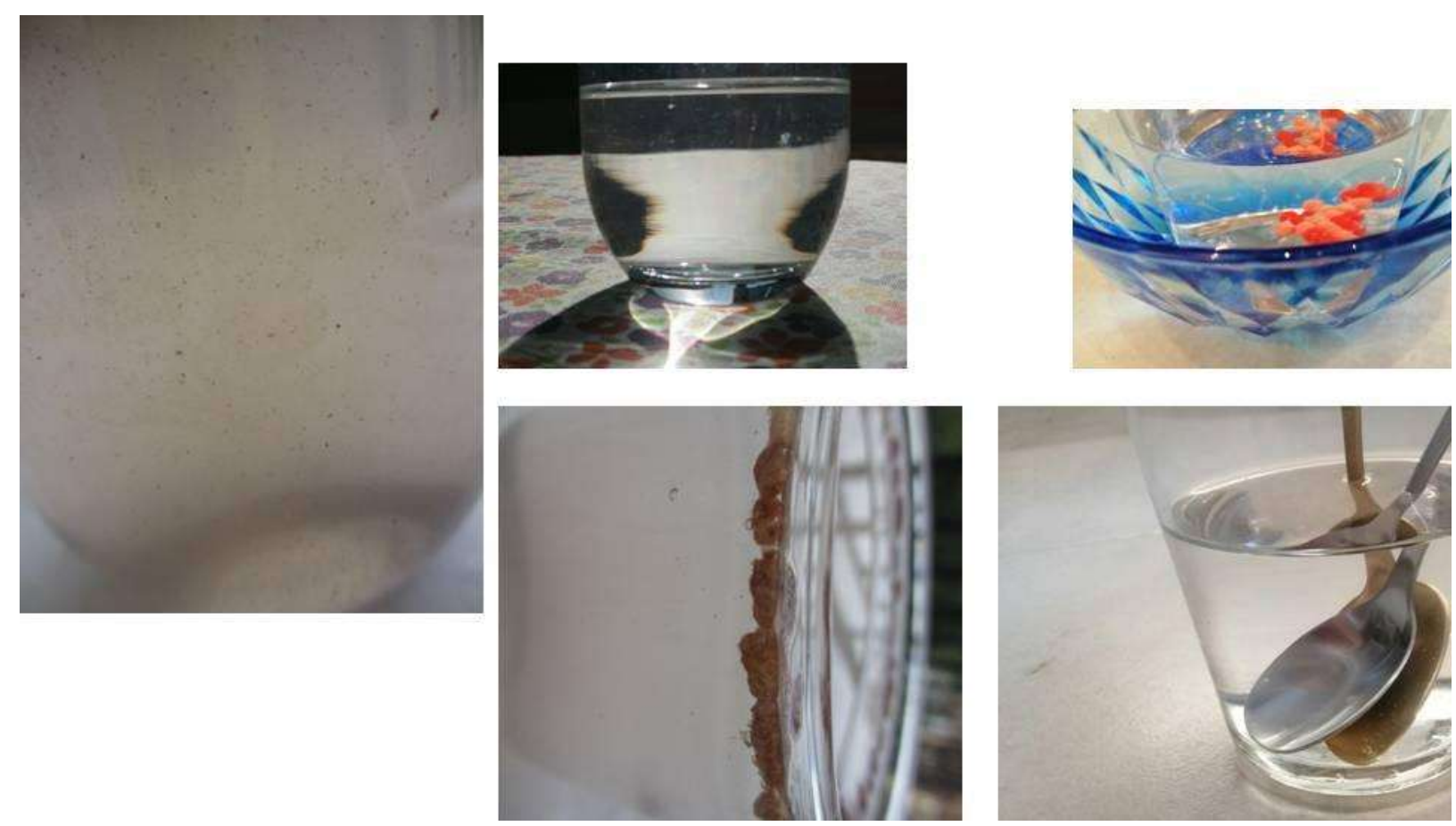

Figura 7. Fotograma 7. Autoría propia.

En cada circunstancia los participantes aportan nuevas perspectivas, influyen, resignifican el espacio, la huella queda trazada. 


\section{Tercio Creciente}

ISSN: 2340-9096

https://doi.org/10.17561/rtc.extra5.5758
Revista de Estudios en Sociedad, Artes y Gestión Cultural

\section{@}
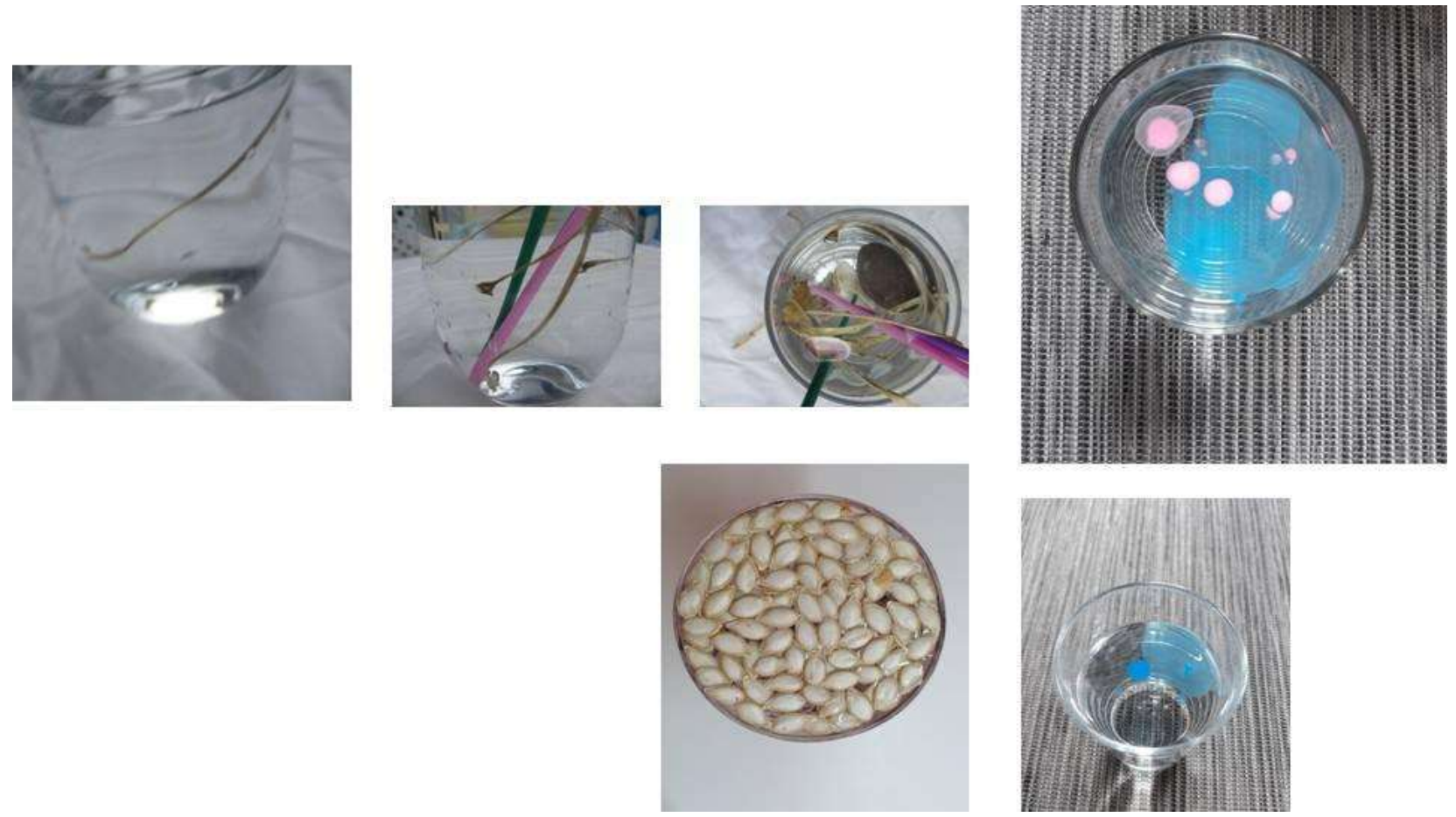

Figura 8. Fotograma 8. Autoría propia.

Cuando el estado líquido emerge en un contexto inesperado a veces es visitado por aquello que lo encuentra extraño. Lo mira y valora, a veces amigo, a veces reticente.

Y todo para que quizá al final nuestra agua pierda su transparencia, pero eso siempre será sinónimo de un recuerdo, recuerdo de lo ocurrido, de lo vivido. 


\section{Conclusiones}

Poner en relación nuestras concepciones y nuestro posicionamiento docente utilizando una metáfora visual supone un cambio en el modo de acercarnos al conocimiento. De esta manera, se plantea un lugar donde la divergencia se abre camino a ser reinterpretada y, también, vinculada.

El modo de hacer elegido aboga por construir un diálogo en relación, donde el discurso de uno puede nutrir la creación del otro, donde las ideas propias y ajenas no deben ser explicadas porque son percibidas visualmente y fácilmente comprendidas, donde lo significativo queda representado. Por lo tanto, trabajar a través del fotoensayo se presta a la resignificación continua.

Por otro lado, la vivencia artística aporta nuevos matices y pliegues desde los que seguir repensandonos, en una comunicación representativa y expresiva que nos ayuda a sentir y entender lo líquido como un modo de comprender el espacio y favorece la necesidad de corporeizarnos en él y hacerlo nuestro.

Sin embargo, este posicionamiento personal y pedagógico se confronta con la era covid. Un indeseable elemento imperceptible a la vista ha ocupado numerosos espacios, cuestionado la seguridad y removido los cimientos de la sociedad mundial. Toca vivir en incertidumbre continua y mantenerse si no aislado, sí respetando unas distancias que perjudican enormemente las relaciones, la escucha, la calma... Desde esta vivencia entendemos que continúa estando presente la influencia del espacio en nuestras maneras de ver, oír, sentir... aprender y vivir. Por ello, recogemos estos matices y los valoramos como posibles ramificaciones desde las que poder reflexionar y generar modos de hacer en nuestra práctica investigadora y docente.

Pensamos que pequeños cambios pueden contribuir a una nueva vivencia, concepción y corporeidad del espacio, donde se construyan lugares de comunicación, colaboración y encuentro, de intercambio, de aprendizaje y se produzcan nuevas maneras de habitabilidad en un espacio cuidado y de autocuidado que genere vínculo, pertenencia, aporte significados y produzca recuerdos. Un espacio habitado de manera natural, poseedor de aspectos biográficos y retratos individuales y colectivos, ya que al fin y al cabo eso será lo que contribuya a la construcción de vivencias vitales significativas. 


\section{Referencias}

Barone, T. y Eisner, E. W. (2012). Arts Based Research. California: Sage.

Bauman, Z. (2006). Vida líquida. Barcelona: Paidós.

Careri, F. (2002). Walkscapes. El andar como práctica estética. Barcelona: Gustavo Gili.

Di Masso, Andrés; Berroeta, Héctor \& Vidal, Tomeu (2017). El espacio público en conflicto: Coordenadas conceptuales y tensiones ideológicas. Athenea Digital, 17(3), 53-92. https://doi.org/10.5565/rev/athenea.1725

Huerta, R. y Domínguez, R. (2015). Investigar sobre los entornos educativos y abordar la problemática situación de la educación artística en secundaria. EARI, Educación artística revista de investigación, 6, 10-18. htp://dx.doi.org/10.7203/eari.6.6887

Jornet, A. y Erstad, O. (2018). From learning contexts to learning lives: Studying learning (dis) continuities from the perspective of the learners. Digital Education Review. №33, June 2018, 125. https://revistes.ub.edu/index.php/der/article/view/21810/pdf

Müller, T. (2010). The third teacher. Collaborative Project: OWP/ P Architects +Vs Furniture + Bruce Mau Design. New York: Abrams.

Pérez Fernández, F. (2004). El medio social como estructura psicológica. Reflexiones a partir del modelo ecológico de Bronfenbrenner. Edupsykhé. Revista de psicología y psicopedagogía, 3(2), 161-177.

Roldan Ramirez, J y Marín Viadel, R. (2012). Metodologías artísticas de investigación en educación. Archidona: Aljibe. 
